\title{
Subsidy-Related Deception Behavior in Energy-Saving Products Based on Game Theory
}

\author{
Ni Zhao, Tongshui Xia, Tao Yu* and Changyu Liu* \\ Business School, Shandong Normal University, Jinan, China
}

The appropriate use of subsidies is the key to promote the development of energy-saving products (ESPS). However, subsidy-related deception behavior frequently occurs. Considering the relevant stakeholders, a game model including governments' subsidy policies, manufacturers' environmental quality measures, and customer environmental awareness (CEA) was constructed. We analyzed the crucial influencing factors of governments' and manufacturers' strategies. Quantitative analyses were performed to verify the modeling analyses and to demonstrate the influence of the game parameters. The results indicate that government regulation is necessary to keep manufacturers honest. Increases in penalties, the subsidy coefficient, environmental quality, and CEA all promoted manufacturer integrity. The results further reveal that the equilibrium probability of manufacturer's integrity decreased with both the sales price of ESPs and the cost of government inspections. Moreover, as the cost coefficient of ESPs increased, the government enhanced the relevant regulations. Collectively, these results suggest strategies to reduce subsidy-related deception behavior and improve the effectiveness of government regulations.

\begin{abstract}
Keywords: government regulation, energy-saving product, subsidy policy, deception behavior, payoff matrix, game model
\end{abstract}

Astronautics, China

*Correspondence:

Tao Yu

yut@sdnu.edu.cn Changyu Liu

sdliuchangyu@126.com

Specialty section: This article was submitted to Sustainable Energy Systems and

Policies,

a section of the journal Frontiers in Energy Research

Received: 22 September 2019 Accepted: 09 December 2019 Published: 09 January 2020

Citation: Zhao N, Xia T, Yu T and Liu C (2020) Subsidy-Related Deception Behavior in Energy-Saving Products Based on Game Theory.

Front. Energy Res. 7:154. doi: 10.3389/fenrg.2019.00154

\section{INTRODUCTION}

Products with energy-saving and carbon emissions-reducing features, such as those that cover the hourly electricity consumption of household appliances and electric vehicles with low carbon emissions, can be referred to as energy-saving products (Ji and Zhang, 2019; Li et al., 2019). In this paper, we discuss the carbon emissions attribute of ESPs. Due to the growing ecological problems associated with environmental deterioration, resource depletion, and energy shortages, ESPs are now receiving significant attention from governments, consumers, and manufacturers worldwide (Zhang D. Y. et al., 2019). To stimulate the development of ESPs, a series of government regulation policies, such as tax reduction, subsidies, and cap and trade, have been issued to manufacturers and consumers (Liu and $\mathrm{Yu}, 2019$ ). Indeed, financial subsidies directly offered by governments play a critical role in the stimulation of ESP manufacturing (Tang and Zhou, 2012; Song et al., 2018). In the United States, for example, the federal government has regulated the emissions of automobiles for decades, and in December 2015, the State Council of the People's Republic of China announced that 33.4 billion CNY had been earmarked to subsidize the production of vehicles with low carbon emissions. In addition, the Chinese government also invested 26.5 billion CNY in financial subsidies, which successfully promoted energy-saving household appliances. Similar subsidy schemes have also been implemented by European governments. Due to increasing customer environmental awareness 
(CEA), customers are now more familiar with low carbon emission products, and they are willing to pay extra for ESPs (Paksoy and Ozceylan, 2014; Chander and Muthukrishnan, 2015). Therefore, many manufacturers actively seek to improve their economic and environmental performance, and they engage in the ESP market to gain a competitive advantage.

The current trend in ESP development is not without obstacles and risks. It is well known that both the design and the production of ESPs bear high levels of risk and uncertainty. Research and development of low carbon technologies are often extremely costly. Subsidy policies that intend to reduce production costs lead to subsidy-related deception behavior (Bonroy and Constantatos, 2015). To attract the growing environmentally aware consumer segment and to obtain the huge financial subsidies offered by governments, some manufacturers promote their products as green products, but such claims may be false or misleading (Nyilasy et al., 2014). The products in question may not reflect the attributes or performance associated with ESPs, such as quality and safety. In 2016, the Ministry of Finance of the People's Republic of China conducted a special inspection of automobile manufacturers and discovered that the production of 76,000 new and supposedly energysaving automobiles was associated with the fraudulent payment of up to 9.27 billion CNY. In 2015, the US Environmental Protection Agency announced that Volkswagen had installed exhaust emission detection software in its vehicles that violated government regulations, which resulted in daily emissions of nitrogen oxides that were approximately 40 times higher than the statutory standard.

It is clear that subsidy-related deception behaviors, such as those described above, can seriously harm society, and consumers. Such behaviors lead to a loss of competitive advantage for manufacturers that adhere to the requirements to receive subsidies. Governments cannot afford to support high-level manufacturers due to subsidies paid to fraudulent manufacturers. Additionally, these types of deception behaviors can cause consumers to question manufacturer integrity (Parguel et al., 2015; Paul et al., 2016). Therefore, the issue of subsidyrelated deception behaviors requires urgent attention. To reduce the incidence of deception behaviors and to stabilize the development of ESPs, the present paper aimed to answer the following research questions.

1. With respect to financial intervention by governments to promote the development of ESPs, what factors motivate manufacturers to fraudulently obtain subsidies?

2. How do manufacturers respond to the punishments and increased subsidy standards instituted by governments?

3. Will greater CEA and environmental quality reduce manufacturer subsidy-related deception behaviors?

Considering the interactions that occur among CEA, product environmental quality, and government subsidy policies, a game model involving manufacturers and governments was constructed to answer these questions. Furthermore, to better understand the relationship between the manufacturer and government equilibrium probabilities, simulations and sensitivity analyses of the model were performed. This paper also examines how governments should set subsidies considering manufacturer subsidy-related deception behaviors. From the Nash equilibrium probabilities of the players, we determined that punishment, environmental quality, subsidies, and CEA are all key influencing factors for manufacturer and government strategy selection.

The remainder of this paper is organized as follows. After a review of the relevant literature in section Literature Review, the model formulation and solution procedure are described in section Problem Assumptions and Model Development. Section Numerical Examples presents quantitative analyses of the equilibrium probabilities. Finally, section Conclusions and Suggestions for Future Research describes the conclusions of the research and the implications of the findings.

\section{LITERATURE REVIEW}

The literature reviewed here primarily relates to three research streams: the effect of regulation policies on ESPs, the dishonest behaviors of manufacturers, and CEA of manufacturer production. Key studies from the different research streams are briefly reviewed in the following subsections.

\section{Government Regulations on ESPs}

As increasingly more regulations to protect the environment are issued, much research has been performed on how these regulations affect manufacturers' environmental performance and operations management (Song et al., 2019; Xia et al., 2019). Regulations such as carbon taxes, subsidies, and cap and trade certainly provide substantial motivation for manufacturers to curb emissions (Chen, 2001; Kroes et al., 2012; Gong and Zhou, 2013; Liao and Shi, 2018; Liu C. Y. et al., 2019). The authors of some studies sought to identify optimal operations decisions and to analyze the impact of regulation policies on production decisions. Xue et al. (2019) examined centralized and decentralized decision-making models within a green supply chain for ESPs with government subsidies. Tao et al. (2014) discussed the effective quantitative evaluation of energy-saving and emission-reducing production.

More recently, game theory has been used to model manufacturers' responses to emissions regulations (Liu and $\mathrm{Yu}$, 2015; Xu L. et al., 2019; Xu X. F. et al., 2019). Huang et al. (2019) analyzed a government subsidy scheme that encouraged manufacturers to optimize price and energy efficiency. Barari et al. (2012) used an evolutionary game method to analyze the mechanisms of competition and cooperation between manufacturers and retailers and to identify the ideal balance between net profit and low carbon production. Zhou and Huang (2016) discussed fixed-type contracts and discount-type contracts for ESPs in a monopoly with the government's subsidy budget constraints. Hafezalkotob (2015) explored three-level game theory to demonstrate how the government acts as a Stackelberg leader by offering subsidies and tax strategies for green supply chains. Madani and Rasti-Barzoki (2017) and Zhang et al. (2018) developed game models to determine the effect of governmental fixed and discounted subsidies on ESP manufacturers. 


\section{Manufacturers' Dishonest Behavior}

Manufacturers may engage in multiple dishonest behaviors, which primarily include fraud, the misuse of eco-labels, and the use of counterfeit products. These issues are the subject of longterm research, as the problem is global (Hamilton and Zilberman, 2006; Lee et al., 2018). Ibanez and Grolleau (2008) proposed that a polluting firm may also claim eco-labels by paying a fee because consumers cannot observe production technology or pollution related to production. Lyon and Montgomery (2015) explained that greenwashing is a broad term that encompasses many forms of misleading environmental communications. Zu et al. (2018) used a Stackelberg game to examine a two-echelon supply chain consisting of one manufacturer and one supplier and compared the sustainable profits of efforts to reduce $\mathrm{CO}_{2}$ emissions in environmental regulation. Jin et al. (2018) proposed that enterprises should be supervised and regulated after certification. Without effective supervision and regulations, enterprises may cease to implement standards after being certified. Goh and Balaji (2016) used structural equation modeling to investigate the role of skepticism in green purchase behaviors and emphasized that skepticism reduced consumers' knowledge and environmental concerns, which then decreased their intention to purchase green products.

\section{Customer Environmental Awareness}

Another relevant research stream is the CEA of manufacturers' product design and pricing. Most studies on these topics have revealed that CEA influences manufacturers' carbon reduction strategies (Liao et al., 2019; Liu Y. X. et al., 2019). For example, Yalabik and Fairchild (2011) discovered that when there are environmentally sensitive customers, manufacturers are incentivized to reduce carbon emissions through investment in green technology. Liu et al. (2012) investigated the impact of CEA on supply chain players and manufacturer competition. Zhang et al. (2015) also considered the impact of CEA on firms' operations decisions, such as optimal ordering policies and coordination contracts, and firms' economic and environmental performance. Li and Li (2016) analyzed consumers' preferences for low carbon products and concluded that retailers are motivated to promote low carbon products whether or not manufacturers are incentivized to produce them. Hammami et al. (2018) studied the effect of CEA on emission intensity and product price and discovered that CEA efficiently drives better environmental performance. Zhang Y. X. et al. (2019) identified the influencing factors for products, consumers, and regulations based on energy-saving appliances. There is evidence that manufacturers are willing to invest in green technology and reduce carbon emissions when they realize that consumers prefer environmentally friendly products (Sengupta, 2015; Xu and Wang, 2018).

Based on the existing research, we made conclusions about the relationships among governments, manufacturers, and consumers of ESPs, which are illustrated in Figure 1. During the entire production of ESPs, governments, manufacturers, and consumers were key influencing factors. Therefore, we considered the effect of CEA on the joint environmental quality of ESPs and governmental subsidies. Most of the previous studies on ESPs focused on how to design contracts to encourage stakeholders. However, the prevention of deceptive behaviors to obtain subsidies, which is a severe problem in practice, was rarely discussed in depth. In this paper, we used game theory to discuss the crucial influencing factors of manufacturer subsidy-related deception behaviors.

\section{PROBLEM ASSUMPTIONS AND MODEL DEVELOPMENT}

\section{Problem Assumptions}

Several model assumptions have been used to analyze manufacturers' attempts to fraudulently obtain government subsidies. We assumed that a monopolist provides two kinds of durable products with different carbon emissions: ESPs and traditional products (TRPs). Both of these types of products emit carbon dioxide when they are used. Carbon emission is

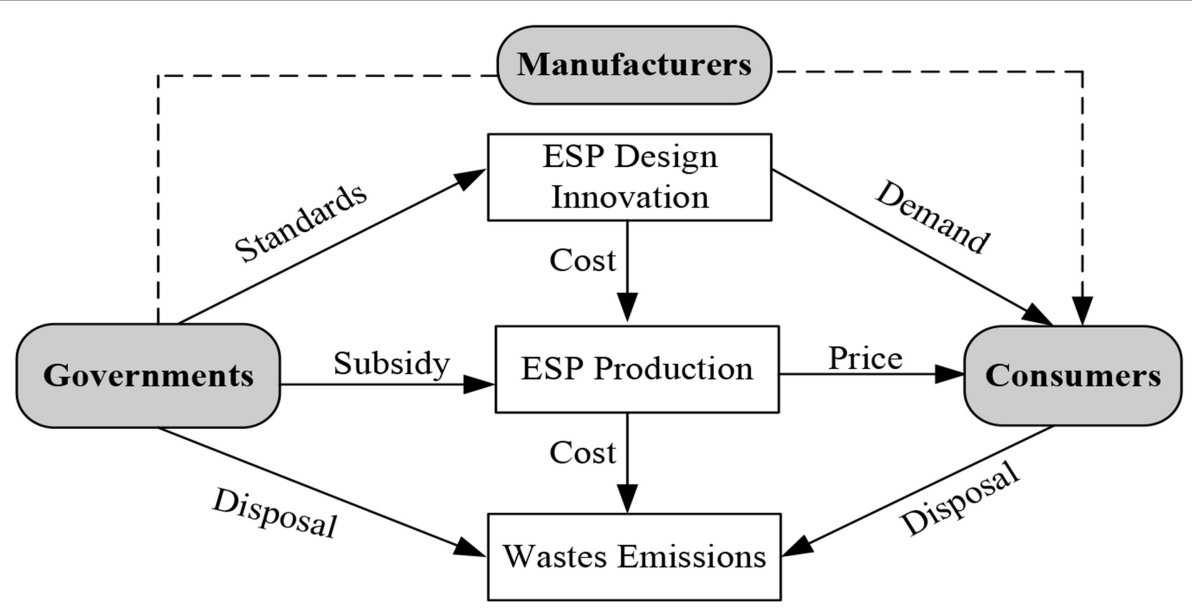

FIGURE 1 | The relationships among governments, manufacturers, and consumers of ESPS. 
denoted by $M(M>0)$. Herein, $M_{E}$ and $M_{T}$ represent the carbon emissions of ESPs and TRPs, respectively. ESPs have lower carbon emissions, that is, $M_{E}<M_{T}$. For example, the choice to drive an electric vehicle rather than a traditional fuel vehicle can help reduce carbon emissions by approximately 30 tons per year (Sulman et al., 2009).

The market demand for ESPs is denoted by $D$ and expressed by the following equation: $D=a-b p+\xi e(a>0, b>0)$. In this equation, $a$ is the primary demand for ESPs; $p$ is the product's sale price; $b$ is the sensitivity to the sale price; $e$ is environmental quality; $\xi$ is CEA; and $a-b p>0$. Market demand increases with CEA and with the environmental quality of ESPs, and it decreases as price increases (Liu et al., 2012).

The manufacturer can only receive governmental subsidies when a product's carbon emissions meet certain energy-saving standards. The carbon emissions standard is expressed by $\left[\underline{M}, M_{0}\right]$. If $M<M_{0}$, the manufacturer can receive the subsidy. In this paper, we define environmental quality, $e$, as $e=\frac{M_{0}-M}{M_{0}}$. In contrast to ESPs, TRPs do not have environmental quality, and higher values of $e$ demonstrate better environmental quality.

The subsidy coefficient is $\varphi$, and the subsidy for manufacturers that produce ESPs is $\varphi$ e. Government budgets are limited, so the upper bound of the subsidy is $\Lambda$. If $M<\underline{M}$, the total subsidy cannot exceed $\Lambda$. The subsidy is calculated using the following equation.

$$
f(\varphi, e)=\left\{\begin{array}{cc}
0 \\
\varphi \frac{M_{0}-M}{M_{0}}\left(a-b p+\xi \frac{M_{0}-M}{M_{0}}\right) \frac{M \geq M_{0}}{M \leq M<M_{0}} \\
\Lambda
\end{array}\right.
$$

Similar to the model by Gouda et al. (2016), the production cost in our model was calculated using a quadratic function, $\frac{1}{2} \mathrm{ce}^{2}$. This function is independent of production volume, and $c$ is a strictly positive cost coefficient.

Governments aim to improve environmental performance, so the government's objective is to minimize total carbon emissions. The benefit coefficient is $k$, and the government's profit is $k\left(M_{0}-\right.$ $\left.M_{E}\right) D$. The cost of supervision and inspection is denoted by $C_{g}$, and special inspections of manufacturers are conducted after obtaining subsidies.

If the manufacturer fraudulently obtains government subsidy, the government's loss is $s\left(M_{T}-M_{E}\right) D$; $s$ represents the loss coefficient. The government will then impose penalties of $(1+$ $f) \varphi e D$ on the manufacturer. For example, a bus company in China received 519 million CNY in financial subsidies in 2015. Fifty percent of this amount was fined a total 800 million CNY based on irregularities. The major parameters of the game model are summarized in Table $\mathbf{1}$.

An optional set of strategies for the government is $\left(a_{1}, a_{2}\right)$ $=$ (regulation, non-regulation). Under the conditions of government regulation and market demand, the set of strategies for manufacturers is $\left(b_{1}, b_{2}\right)=$ (integrity, fraud). The probability of government regulation is $y(0 \leq y \leq 1)$, and the probability of non-regulation is $1-y$. The probability of manufacturer integrity is $x(0 \leq x \leq 1)$, and the probability that manufacturers will obtain subsidies through fraud is $1-x$.
According to the model assumptions, two players simultaneously choose one of the two possible strategies, and there are four combinations of strategies for the government and the manufacturer. The payoff matrix of the government-manufacturer game is shown in Table 2 .

\section{Model Analysis}

In this section, we review the equilibrium probability calculated for this game and analyze the factors influencing manufacturers' and governments' strategy choices.

\section{The Nash Equilibrium Probability of Manufacturer}

Theorem 1. The Nash equilibrium probability of manufacturer integrity is $x^{*}$ and is expressed by the following equation: $x^{*}=1-\frac{C_{g}}{(1+f) \varphi e(a-b p+\xi e)}$.

Proof of Theorem1: The expected utility of government regulation and non-regulation are denoted by $V_{g 1}$ and $V_{g 2}$, respectively, and are expressed by the following equations.

$$
\begin{aligned}
& V_{g 1}=x\left\{\left[k\left(M_{0}-M_{E}\right)-\varphi e\right](a-b p+\tau e)-C_{g}\right\} \\
& \quad+(1-x)\left\{\left[(1+f) \varphi e-s\left(M_{T}-M_{E}\right)\right](a-b p+\xi e)-C_{g}\right\} \\
& V_{g 2}=x\left\{\left[k\left(M_{0}-M_{E}\right)-\varphi e\right](a-b p+\xi e)\right\} \\
& \quad+(1-x)\left[-s\left(M_{T}-M_{E}\right)(a-b p+\xi e)\right]
\end{aligned}
$$

\begin{tabular}{|c|c|c|c|}
\hline & & \multicolumn{2}{|c|}{ Government } \\
\hline & & Regulation, y & Non-regulation, $1-y$ \\
\hline \multirow[t]{2}{*}{$\begin{array}{l}\text { Manu- } \\
\text { facturer }\end{array}$} & $\begin{array}{l}\text { Integrity, } \\
x\end{array}$ & $\begin{array}{l}(p+\varphi e)(a-b p+\xi e)-\frac{1}{2} c e^{2} \\
{\left[k\left(M_{0}-M_{E}\right)-\varphi e\right](a-b p+} \\
\xi e)-C_{g}\end{array}$ & $\begin{array}{l}(p+\varphi e)(a-b p+\xi e)- \\
\frac{1}{2} c e^{2}\left[k\left(M_{0}-M_{E}\right)-\varphi e\right](a- \\
b p+\xi e)\end{array}$ \\
\hline & $\begin{array}{l}\text { Fraud, } \\
1-x\end{array}$ & $\begin{array}{l}{[p-(1+f) \varphi e](a-b p+} \\
\xi e)\left[(1+f) \varphi e-s\left(M_{T}-M_{E}\right)\right]\end{array}$ & $\begin{array}{l}(p+\varphi e)(a-b p+\xi e)- \\
s\left(M_{T}-M_{E}\right)(a-b p+\xi e)\end{array}$ \\
\hline
\end{tabular}

TABLE 1 | The parameters of the game model.

\begin{tabular}{ll}
\hline Parameters & Description \\
\hline$e$ & Environmental quality \\
$\varphi$ & Coefficient of the manufacturer subsidy \\
$M_{E}, M_{T}$ & Carbon emissions of ESPs and TRPs, respectively \\
$M_{0}$ & Subsidy standard for carbon emissions \\
$p$ & Product sales price \\
$c$ & Cost coefficient of ESPs \\
$f$ & Government penalty coefficient \\
$k$ & Government benefit coefficient \\
$s$ & Government loss coefficient \\
$C_{g}$ & Cost of supervision and inspection \\
$a$ & Primary demand for ESPs \\
$b$ & Coefficient for the sensitivity of demand to price \\
$\xi$ & Consumer environmental awareness \\
\hline
\end{tabular}

TABLE 2 | The payoff matrix for the government and the manufacturer. 
When $V_{g 1}=V_{g 2}$, we calculated that $x^{*}=1-\frac{C_{g}}{(1+f) \varphi e(a-b p+\xi e)}$. Therefore, the Nash equilibrium probability of fraud can be expressed as $1-x^{*}=\frac{C_{g}}{(1+f) \varphi e(a-b p+\xi e)}$.

Theorem 1 presents the Nash equilibrium probability of manufacturer integrity. This probability is determined by the cost of supervision and inspection, government penalty coefficient, environmental quality, manufacturer subsidy coefficient, and demand for the product.

The probability of manufacturer integrity is expressed by $x^{*}=1-\frac{C_{g}}{(1+f) \varphi e(a-b p+\xi e)}$. When $x>x^{*}$, the government's optimal strategy is non-regulation. When $x<x^{*}$, the government's optimal strategy is regulation. When $x=x^{*}$, it does not matter which strategy the government chooses.

Proposition 1: The probability of manufacture integrity, $x^{*}$, decreases as supervision cost, $C_{g}$, and sale price, $p$, increase.

Since $x^{*}=1-\frac{C_{g}}{(1+f) \varphi e(a-b p+\xi e)}$, the first derivative of the probability of manufacture integrity on $C_{g}$ and $p$ is as follows:

$$
\begin{aligned}
& \frac{\partial x^{*}}{\partial C_{g}}=-\frac{1}{(1+f) \varphi e(a-b p+\xi e)}<0 ; \\
& \frac{\partial x^{*}}{\partial p}=\frac{-C_{g} b(1+f) \varphi e}{[(1+f) \varphi e(a-b p+\xi e)]}<0 .
\end{aligned}
$$

Proposition 1 shows that the Nash equilibrium probability of manufacture integrity decreases when the government spends substantial funds on supervision. In other words, the higher the cost of regulation, the less likely it is that governments will be willing to make regulations. Manufacturers will recognize this scenario, which reduces the necessity to obtain subsidies honestly and decreases the integrity of manufacturers.

The higher the sale price of the ESPs, the more likely manufacturers are to commit fraud. ESP manufacturers who have the potential to gain more profits are more motivated to fraudulently obtain government subsidies.

Proposition 2: The Nash equilibrium probability of manufacture integrity, $x^{*}$, increases as the penalty coefficient, $f$, environmental quality, $e$, the subsidy coefficient, $\varphi$, and CEA, $\xi$, increase.

The first derivative of the Nash equilibrium probability of the manufacturer in terms of $f, e, \varphi$, and $\xi$ was obtained as follows:

$$
\begin{aligned}
\frac{\partial x^{*}}{\partial f} & =\frac{C_{g} \varphi e(a-b p+\xi e)}{[(1+f) \varphi e(a-b p+\xi e)]^{2}}>0 ; \\
\frac{\partial x^{*}}{\partial e} & =\frac{C_{g}[(1+f) \varphi(a-b p+2 \xi e)]}{[(1+f) \varphi e(a-b p+\xi e)]^{2}}>0 ; \\
\frac{\partial x^{*}}{\partial \varphi} & =\frac{C_{g}(1+f) e(a-b p+\xi e)}{[(1+f) \varphi e(a-b p+\xi e)]^{2}}>0 ; \text { and } \\
\frac{\partial x^{*}}{\partial \xi} & =\frac{C_{g}(1+f) \varphi e^{2}}{[(1+f) \varphi e(a-b p+\xi e)]^{2}}>0 .
\end{aligned}
$$

Proposition 2 shows that if the penalty, the subsidy coefficient, environment quality, and CEA increase, the Nash equilibrium probability of manufacture integrity improves.
The higher the penalty, the lower the probability the manufacturer will fraudulently obtain the subsidy. We also demonstrated that improving environment quality increases the Nash equilibrium probability of manufacture integrity. Since $e=\frac{M_{0}-M}{M_{0}}$, if the government enhances the subsidy standard, $M_{0}$, for ESPs, environment quality will improve, and the Nash equilibrium probability of manufacturer integrity will increase.

If CEA is high, ESP demand is also high. If manufacturers do not produce qualified ESPs, consumer complaints will increase. Therefore, honest efforts to obtain government subsidies are the manufacturer's optimal strategy.

\section{The Nash Equilibrium Probability of the Government}

Theorem 2. The Nash equilibrium in governmental regulatory strategies is $y^{*}$ and is expressed by the following equation: $y^{*}=\frac{c e}{(4+2 f) \varphi(a-b p+\xi e)}$.

Proof of Theorem 2: The expected utility of integrity is $V_{m 1}$ and is expressed by the following equation:

$$
\begin{aligned}
V_{m 1} & =y\left[(p+\varphi e)(a-b p+\xi e)-\frac{1}{2} c e^{2}\right] \\
& +(1-y)\left[(p+\varphi e)(a-b p+\xi e)-\frac{1}{2} c e^{2}\right]
\end{aligned}
$$

The expected utility of fraud to the manufacturer is $V_{m 2}$ and is expressed by the following equation:

$$
\begin{aligned}
V_{m 2} & =y\{[p-(1+f) \varphi e](a-b p+\xi e)\} \\
& +(1-y)[(p+\varphi e)(a-b p+\xi e)]
\end{aligned}
$$

When $V_{m 1}=V_{m 2}$, we can calculate the Nash equilibrium probability of the government's strategy, $y^{*}$, using the following equation: $y^{*}=\frac{c e}{(4+2 f) \varphi(a-b p+\xi e)}$.

The equilibrium probability of the government depends on the production cost coefficient, $c$, environmental quality, $e$, the penalty coefficient, $f$, the subsidy coefficient, $\varphi$, and the demand for ESPs.

The probability of government regulation of manufacturers is expressed by the following equation: $y^{*}=\frac{c e}{(4+2 f) \varphi(a-b p+\xi e)}$. When $y>y^{*}$, the manufacturer's optimal strategy is to adhere to government regulations. When $y<y^{*}$, the manufacturer's optimal strategy is fraud. If $y=y^{*}$, it makes no difference which strategy the manufacturer selects.

Proposition 3: The equilibrium probability of government regulation, $y^{*}$, decreases as the manufacturer penalty, $f$, the subsidy coefficient, $\varphi$, and CEA, $\xi$, increase.

The solutions for $f, \varphi$, and $\xi$ for the first derivatives of $y^{*}$ are as follows:

$$
\begin{aligned}
& \frac{\partial y^{*}}{\partial f}=\frac{-2 c e \varphi(a-b p+\xi e)}{[(4+2 f) \varphi(a-b p+\xi e)]^{2}}<0 \\
& \frac{\partial y^{*}}{\partial \varphi}=\frac{-(4+2 f) c e(a-b p+\xi e)}{[(4+2 f) \varphi(a-b p+\xi e)]^{2}}<0
\end{aligned}
$$

and

$$
\frac{\partial y^{*}}{\partial \xi}=\frac{-(4+2 f) c \varphi e^{2}}{[(4+2 f) \varphi(a-b p+\xi e)]^{2}}<0
$$


Proposition 3 demonstrates that as the subsidy, CEA, and the penalty for fraud increase, the probability of government regulation decreases. The reverse is also true.

The higher the penalty, the more the government deters manufacturers from committing fraud. This phenomenon reduces the need for government supervision and reduces the probability of quality supervision. The reverse is true as well.

As the government subsidy coefficient increases, subsidy expenditures increase as well. Furthermore, as supervision cost increases, the intensity of government supervision decreases.

When CEA is high, the need for government supervision decreases. Therefore, improving CEA can effectively reduce the pressure to implement government supervision.

Proposition 4: The probability of government regulation $y^{*}$, increases as the production cost coefficient, $c$, the price of ESPs, $p$, and environmental quality, $e$, increase.

The solutions for the first derivative of $y^{*}$ for $c, p$, and $e$ are as follows:

$$
\begin{aligned}
\frac{\partial y^{*}}{\partial c} & =\frac{e}{(4+2 f) \varphi(a-b p+\xi e)}>0 \\
\frac{\partial y^{*}}{\partial p} & =\frac{(4+2 f) c e \varphi b}{[(4+2 f) \varphi(a-b p+\xi e)]^{2}}>0 ;
\end{aligned}
$$

and

$$
\frac{\partial y^{*}}{\partial e}=\frac{(4+2 f) c \varphi(a-b p)}{[(4+2 f) \varphi(a-b p+\xi e)]^{2}}>0
$$

Proposition 4 shows that the higher the production cost, the sale price, and environmental quality of ESPs, the greater the probability of government regulation.

This finding shows that when the cost and price of ESPs are higher, manufacturers are more likely to fraudulently obtain subsidies to increase their profits, and the government is more likely to supervise manufacturers. When government subsidy standards for ESPs are higher, the government is more likely to supervise manufacturers to prevent substandard manufacturers from fraudulently obtaining subsidies.

The changes in equilibrium probability as the model parameters increase are presented in Table 3.

Table 3 displays that the penalty coefficient, $f$, environmental quality, $e$, the subsidy coefficient, $\varphi$, CEA, $\xi$, and the ESPs price, $p$, influence both governments and manufacturers. Therefore, to reduce fraudulent efforts to obtain subsidies, these critical factors should be adjusted to support the desired strategic

TABLE 3 | Changes in equilibrium probability as model parameters increase.

\begin{tabular}{llllllllll}
\hline & Parameters & $\boldsymbol{f}$ & $\boldsymbol{e}$ & $\boldsymbol{\varphi}$ & $\boldsymbol{\xi}$ & $\boldsymbol{p}$ & $\boldsymbol{C}_{\boldsymbol{g}}$ & $\boldsymbol{c}$ \\
\hline $\begin{array}{l}\text { Manufacturer's integrity } \\
\text { equilibrium probability }\end{array}$ & $x^{\star}$ & & + & + & + & + & - & - & 0 \\
$\begin{array}{l}\text { Government's regulation } \\
\text { equilibrium probability }\end{array}$ & $y^{\star}$ & & - & + & - & - & + & 0 & +
\end{tabular}

+, Increase; -, Decrease; 0, No effect. choice. Furthermore, high penalties, high subsidies, and high CEA benefit both manufacturers and governments. Therefore, penalties and subsidies should be increased, and governments should invest in improving CEA.

\section{NUMERICAL EXAMPLES}

To illustrate these conclusions more intuitively, quantitative analyses are presented. Simulations explore the effect of the penalty coefficient, environmental quality, the subsidy coefficient, CEA, and price on the manufacturer and government equilibrium probabilities. This section also further describes the effect of inspection costs on the manufacturer's equilibrium probability and the effect of the ESPs cost coefficient on the government equilibrium probability. For each scenario, a quantitative example is provided to illustrate the change.

For this quantitative demonstration, we assigned values to each parameter based on the assumptions described in the previous sections and the practical implications. The parameters $a=20$ and $b=1$ were used.

\section{The Impact of the Penalty Coefficient, $f$, on Equilibrium Probability}

In this example, $C_{g}=1, \varphi=0.5, e=0.5, p=$ $10, \xi=0.5$, and $c=24$. Herein, we explored the change in both game members' equilibrium probabilities as the government penalty coefficient, $f$, changed. Figure 2 shows that the equilibrium probability of manufacturers increases with $f$ and the government's equilibrium probability decreases as $f$ increases. These results are in accordance with propositions 2 and 3.

As shown in Figure 2, government penalties can effectively control manufacturer dishonesty and ensure the stable development of ESPs. Higher penalties also reduce the probability of regulation, which can decrease the cost of

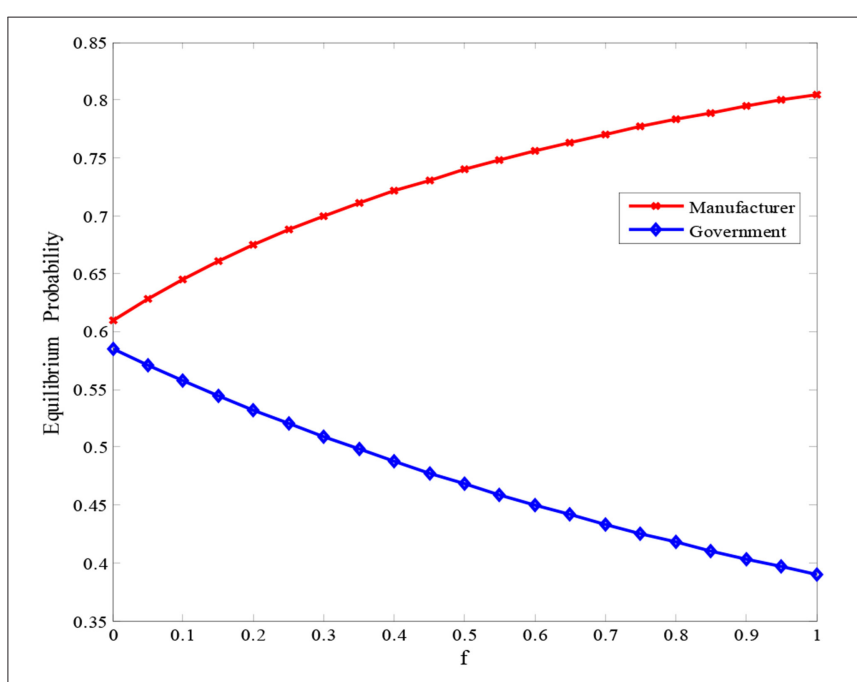

FIGURE 2 | Game members' equilibrium probabilities as a function of $f$. 
government regulation. This relationship reveals the key to increasing penalties for manufacturer fraud.

\section{The Influence of Environmental Quality, e, on Equilibrium Probability}

This section examines the effect of environmental quality, $\boldsymbol{e}$, on equilibrium probability. Herein, $C_{g}=0.5, \varphi=0.5, p=6, f=$ $0.5, \xi=0.5$, and $c=24$. Figure 3 shows that the manufacturer's and the government's equilibrium probabilities increase with $\boldsymbol{e}$. This result is in accordance with propositions 2 and 4 .

Figure 3 shows that improving environmental quality can benefit the manufacturer. It is optimal to produce products that meet the standard defined in the subsidy declaration.

\section{The Impact of the Subsidy Coefficient, $\varphi$, on Equilibrium Probability}

The parameters were assumed as follows: $C_{g}=0.5, e=0.5$, $p=6, f=0.5, \xi=0.5$, and $c=4$. Figure 4 shows that the manufacturer's equilibrium probability increases with $\varphi$, and the government's equilibrium probability decreases as $\varphi$ increases. This result is in accordance with propositions 2 and 3.

Figure 4 demonstrates that when government subsidies increase, manufacturers' dishonest behavior increases as well. Because government budgets are limited, extremely high subsidies affect the regulation cost. Therefore, increased subsidies also decrease the government's motivation to regulate manufacturers.

\section{The Impact of CEA, $\xi$, on Equilibrium Probability}

In this subsection, $C_{g}=0.5, \varphi=0.5, p=18, f=0.5$, $\varphi=0.5$, and $c=24$. This section explores the effect of CEA, $\xi$, on equilibrium probability. Figure 5 shows how CEA, $\xi$, impacts the game members' strategies. The manufacturer's equilibrium probability increases with $\xi$, while the government's equilibrium probability decreases as $\xi$ increases. This result is in accordance with propositions 2 and 3 .

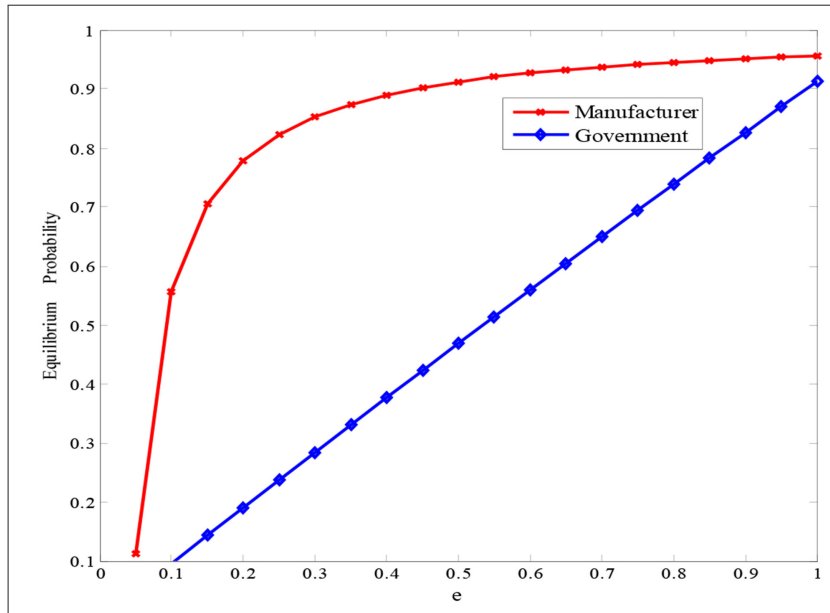

FIGURE 3 | Game members' equilibrium probabilities as a function of e.
As shown in Figure 5, when CEA increases, the probability of manufacturer integrity increases as well. The government benefits from this phenomenon. Therefore, it is a good strategy for the government to improve CEA.

\section{The Impact of Sale Price, $p$, on Equilibrium Probability}

We set the following parameters: $C_{g}=0.5, e=0.5, \varphi=$ $0.5, f=0.5, \xi=0.5$, and $c=60$. Figure 6 shows how price, $p$, impacts game members' strategies. The manufacturer's equilibrium probability decreases as $p$ increases, while the government's equilibrium probability increases with $p$. This result is in accordance with propositions 1 and 4 .

Figure 6 shows that as the ESPs sale price increases, manufacturer dishonesty increases. When the ESP price is
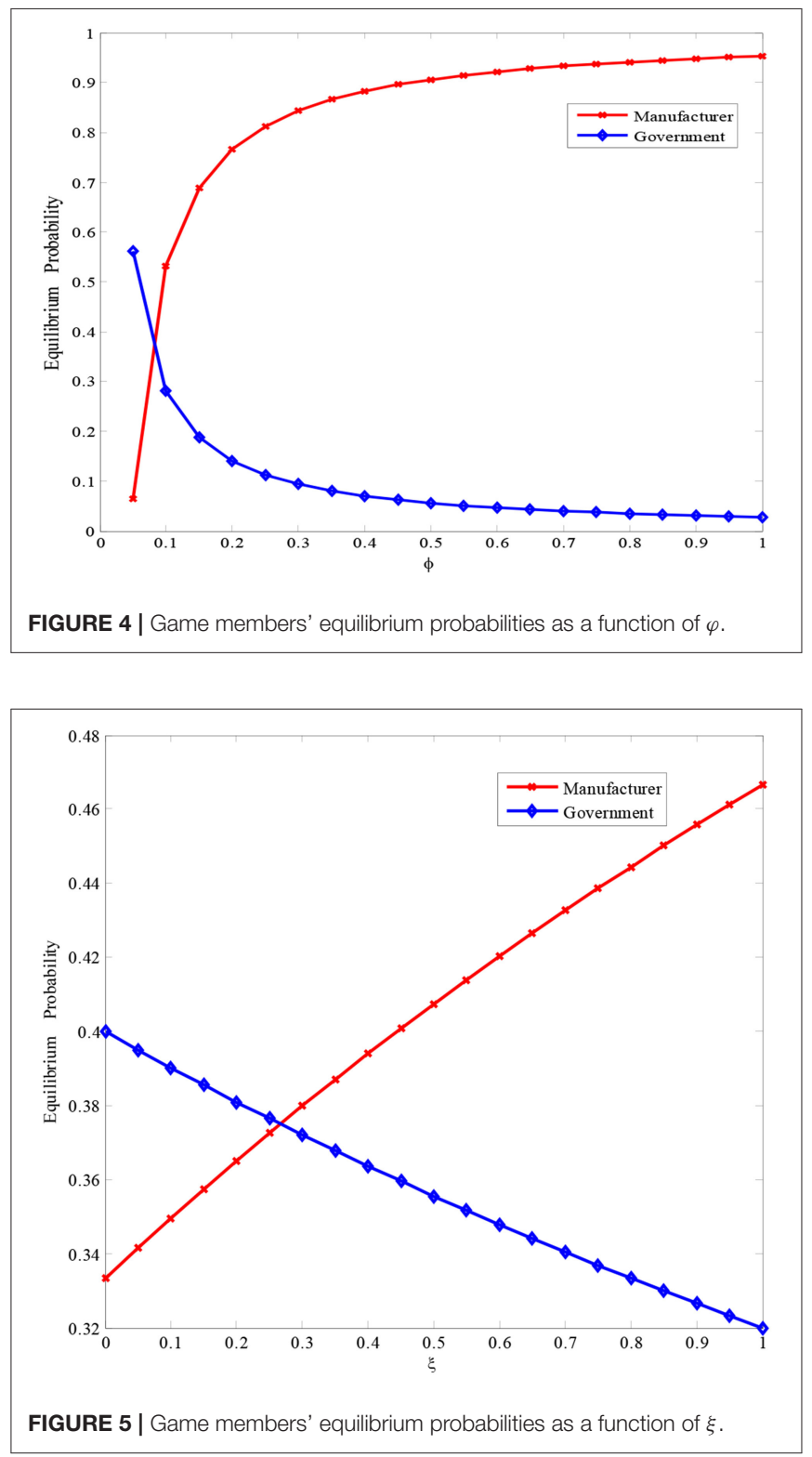


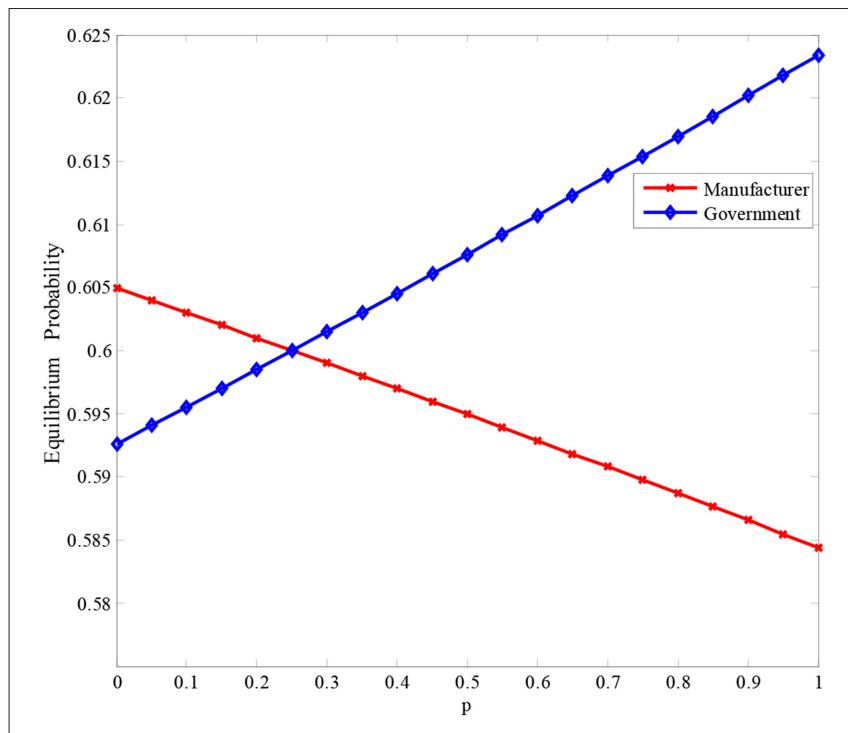

FIGURE 6 | Game members' equilibrium probabilities as a function of $p$.

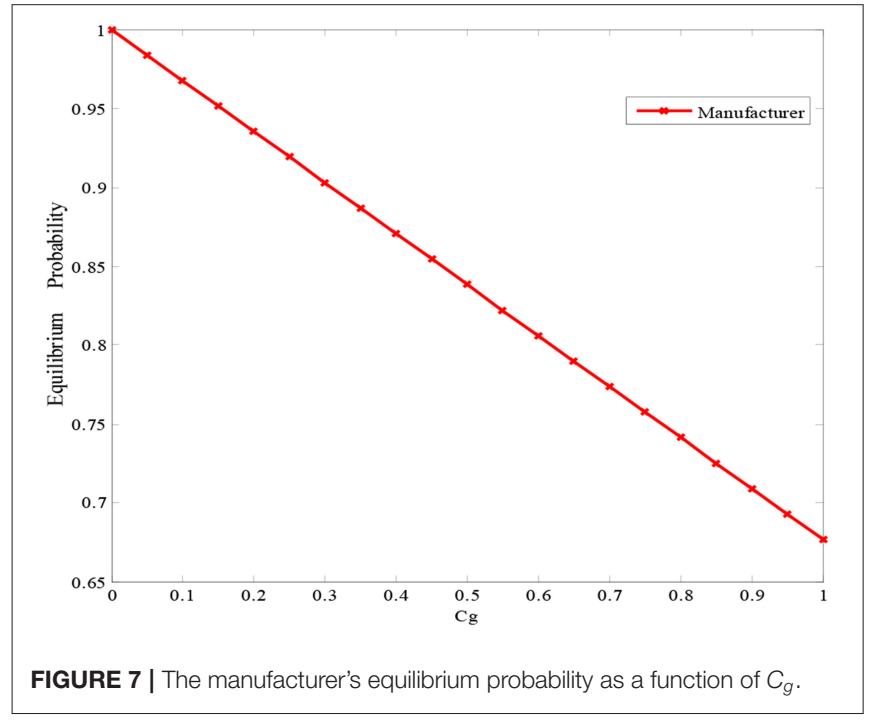

high, the manufacturer is more likely to take the risk of fraudulently obtaining subsidies to gain market share and increase profits.

\section{The Impact of Inspection Cost, $C_{g}$, on the Manufacturer's Equilibrium Probability}

Here $\varphi=0.5, p=12, f=0.5$, and $e=0.5$. Figure 7 shows that the manufacturer's equilibrium probability decreases as the government inspection cost, $C_{g}$, decreases.

Figure 7 shows that if government inspection costs are high, the probability of manufacturer integrity decreases. Therefore, the government should take measures to detect manufacturer subsidy fraud and reduce regulatory costs in this scenario.

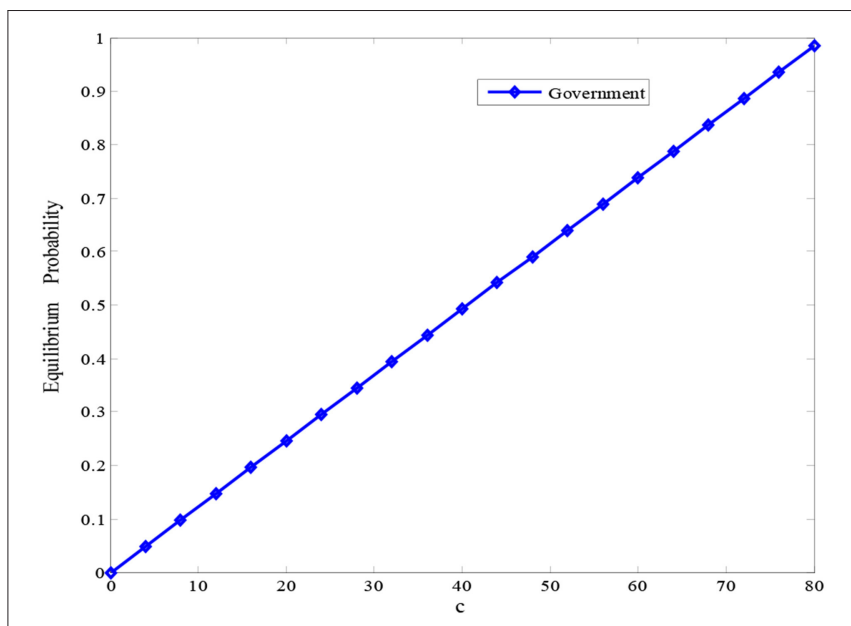

FIGURE 8 | The government's equilibrium probability as a function of $c$.

\section{The Impact of the Cost Coefficient, c, on the Government's Equilibrium Probability}

Here $e=0.5, \varphi=0.5, f=0.5, p=4$, and $\xi=0.5$. Figure 8 shows that as cincreases, the government's equilibrium probability increases as well. In other words, if the production cost of ESPs is extremely high, the probability of government regulation increases.

\section{CONCLUSIONS AND SUGGESTIONS FOR FUTURE RESEARCH}

To improve manufacturers' environmental performance, governments offer financial subsidies to enhance ESP development. This paper discussed the issue of manufacturer fraud to obtain government subsidies. We used theoretical analyses and simulations to identify the factors that impact strategic choices. Considering CEA, environmental quality, and government subsidy policies, a game model was developed to discuss the relationship between governments and manufacturers. The Nash equilibrium probability demonstrates that the penalty coefficient, environmental quality, the subsidy coefficient, the sale price, and CEA were the primary factors influencing players' behavioral strategies. We further used quantitative examples to analyze the change in these parameters. Based on the equilibrium probability, this study can help governments further develop and implement appropriate environmental policies. The following regulation policies are recommended.

First, increased penalties for manufacturer fraud and CEA not only increase the probability of manufacturer integrity but also decrease the probability of government regulation. Therefore, increasing penalties and CEA is beneficial to both players and presents a win-win situation. However, penalties affect manufacturer strategies. It is better for the government to impose penalties on dishonest manufacturers. Manufacturers make greater efforts to reduce emissions when CEA is high. 
The government can also promote greater CEA, which can increase manufacturer integrity and reduce the probability of government regulation.

Second, improving the environmental quality of ESPs can increase manufacturer integrity. Therefore, the standards for carbon reduction affect manufacturers. When subsidies are high, manufacturers are more likely to honestly apply for subsidies. Considering the need for environmental protection and budgetary concerns, therefore, is crucial for governments to set proper standards and subsidy amounts to balance the environment and the economy.

Third, the government's inspection cost is critical to manufacturers' decisions. To reduce the cost and the pressure on government regulation, a multi-stakeholder supervision system that includes the government, the public, and the media should be established to monitor subsidy fraud.

To simplify the problem, we only analyzed the manufacturer and the government and did not consider the supply chain. Future research should address the following aspects: (1) A competitive game, including manufacturers and retailers, and a game model of multi-party participation could be constructed. (2) Although we analyzed CEA, manufacturer product quality, and government subsidy policies, the game model was constructed with complete information. The construction of a dynamic game model with incomplete information will be a direction of further research. (3) It would

\section{REFERENCES}

Barari, S., Agarwal, G., Zhang, W. J., Mahanty, B., and Tiwari, M. K. (2012). A decision framework for the analysis of green supply chain contracts: an evolutionary game approach. Expert Syst. Appl. 39, 2965-2976. doi: 10.1016/j.eswa.2011.08.158

Bonroy, O., and Constantatos, C. (2015). On the economics of labels: how their introduction affects the functioning of markets and the welfare of all participants. Am. J. Agric. Econ. 97, 239-259. doi: 10.1093/ajae/aau088

Chander, P., and Muthukrishnan, S. (2015). Green consumerism and pollution control. J. Econ. Behav. Organ. 114, 27-35. doi: 10.1016/j.jebo.2015.02.013

Chen, C. L. (2001). Design for the environment: a quality-based model for green product development. Manage. Sci. 47, 250-263. doi: $10.1287 / \mathrm{mnsc}$.47.2.250.9841

Goh, S. K., and Balaji, M. S. (2016). Linking green skepticism to green purchase behavior. J. Clean. Prod. 131, 629-638. doi: 10.1016/j.jclepro.2016.04.122

Gong, X. T., and Zhou, S. X. (2013). Optimal production planning with emissions trading. Oper. Res. 61, 908-924. doi: 10.1287/opre.2013.1189

Gouda, S. K., Jonnalagedda, S., and Saranga, H. (2016). Design for the environment: impact of regulatory policies on product development. Eur. J. Oper. Res. 248, 558-570. doi: 10.1016/j.ejor.2015.07.043

Hafezalkotob, A. (2015). Competition of two green and regular supply chains under environmental protection and revenue seeking policies of government. Comput. Ind. Eng. 82, 103-114. doi: 10.1016/j.cie.2015.01.016

Hamilton, S. F., and Zilberman, D. (2006). Green markets, eco-certification, and equilibrium fraud. J. Environ. Econ. Manage. 52, 627-644. doi: 10.1016/j.jeem.2006.05.002

Hammami, R., Nouira, I., and Frein, Y. (2018). Effects of customers' environmental awareness and environmental regulations on the emission intensity and price of a product. Decis. Sci. 49, 1116-1155. doi: 10.1111/deci.12302

Huang, W. X., Zhou, W. H., Chen, J. G., and Chen, X. (2019). The government's optimal subsidy scheme under Manufacturers' competition of also be interesting to use relevant cases to conduct an empirical application and analysis of the game models.

\section{DATA AVAILABILITY STATEMENT}

All datasets generated for this study are included in the article/supplementary material.

\section{AUTHOR CONTRIBUTIONS}

All authors contributed to the study conception and design.

\section{FUNDING}

This research was funded by Shandong Provincial Natural Science Foundation (Grant Nos. ZR2017QG003, ZR2016GM10), National Social Science Foundation of China (Grant No. 13AGL012), Shandong Provincial Social Science Foundation (Grant No. 17DGLJ09), and China Postdoctoral Science Foundation (Grant No. 2017M622265).

\section{ACKNOWLEDGMENTS}

The authors gratefully acknowledge the helpful comments and suggestions of the reviewers, which have improved the presentation. price and product energy efficiency. Omega-Int. J. Manage. Sci. 84, 70-101. doi: 10.1016/j.omega.2018.04.006

Ibanez, L., and Grolleau, G. (2008). Can ecolabeling schemes preserve the environment? Environ. Resour. Econ. 40, 233-249. doi: 10.1007/s10640-007-9150-3

Ji, Q., and Zhang, D. Y. (2019). How much does financial development contribute to renewable energy growth and upgrading of energy structure in China? Energy Policy 128, 114-124. doi: 10.1016/j.enpol.2018. 12.047

Jin, J., Zhuang, J., and Zhao, Q. H. (2018). Supervision after certification: an evolutionary game analysis for chinese environmental labeled enterprises. Sustainability 10:1494. doi: 10.3390/su10051494

Kroes, J., Subramanian, R., and Subramanyam, R. (2012). Operational compliance levers, environmental performance, and firm performance under cap and trade regulation. Manuf. Serv. Oper. Manage. 14, 186-201. doi: $10.1287 / \mathrm{msom} .1110 .0357$

Lee, H. C. B., Cruz, J. M., and Shankar, R. (2018). Corporate social responsibility (CSR) issues in supply chain competition: should greenwashing be regulated? Decis. Sci. 49, 1088-1115. doi: 10.1111/deci.12307

Li, J. J., Zhang, J., Zhang, D. Y., and Ji, Q. (2019). Does gender inequality affect household green consumption behaviour in China? Energy Policy 135:111071. doi: 10.1016/j.enpol.2019.111071

$\mathrm{Li}, \mathrm{X}$., and Li, Y. J. (2016). Chain-to-chain competition on product sustainability. J. Clean. Prod. 112, 2058-2065. doi: 10.1016/j.jclepro.201 4.09 .027

Liao, X. C., Shen, S. V., and Shi, X. P. (2019). The effects of behavioral intention on the choice to purchase energy-saving appliances in China: the role of environmental attitude, concern, and perceived psychological. Energy Effic. 1-17. doi: 10.1007/s12053-019-09828-5

Liao, X. C., and Shi, X. P. (2018). Public appeal, environmental regulation and green investment: evidence from China. Energy Policy 119, 554-562. doi: 10.1016/j.enpol.2018.05.020 
Liu, C. Y., and Yu, T. (2015). Study on the tripartite game in quality regulation of green products. China Popul. Resour. Environ. 25, 170-175. doi: 10.3969/j.issn.1002-2104.2015.10.023

Liu, C. Y., and Yu, T. (2019). The regulatory warning model of regional product quality based on the back-propagation artificial neural network. Neural Comput. Appl. 1-10. doi: 10.1007/s00521-019-04188-8

Liu, C. Y., Yu, T., and Ma, Y. H. (2019). Game of government, enterprise and consumer based on product quality regulation perspective. Chin. J. Manage. Sci. 27, 128-130. doi: 10.3724/SP.J.1042.2019.00646

Liu, Y. X., Sun, X., Sun, T., Shi, X. P., and Liu, J. M. (2019). Promoting green residential buildings by increasing homebuyers' willingness to pay: evidence from Sino-Singapore Tianjin Eco-city in China. J. Clean. Prod. 238, 24-30. doi: 10.1016/j.jclepro.2019.117884

Liu, Z. G., Anderson, T. D., and Cruz, J. M. (2012). Consumer environmental awareness and competition in two-stage supply chains. Eur. J. Oper. Res. 218, 602-613. doi: 10.1016/j.ejor.2011.11.027

Lyon, T. P., and Montgomery, A. W. (2015). The means and end of greenwash. Organ. Environ. 28, 223-249. doi: 10.1177/1086026615575332

Madani, S. R., and Rasti-Barzoki, M. (2017). Sustainable supply chain management with pricing, greening and governmental tariffs determining strategies: a game-theoretic approach. Comput. Ind. Eng. 105, 287-298. doi: 10.1016/j.cie.2017.01.017

Nyilasy, G., Gangadharbatla, H., and Paladino, A. (2014). Perceived greenwashing: the interactive effects of green advertising and corporate environmental performance on consumer reactions. J. Bus. Ethics 125, 693-707. doi: 10.1007/s10551-013-1944-3

Paksoy, T., and Ozceylan, E. (2014). Environmentally conscious optimization of supply chain networks. J. Oper. Res. Soc. 65, 855-872. doi: 10.1057/jors.2012.95

Parguel, B., Benoit-Moreau, F., and Russell, C. A. (2015). Can evoking nature in advertising mislead consumers? The power of 'executional greenwashing'. Int. J. Advert. 34, 107-134. doi: 10.1080/02650487.2014.996116

Paul, J., Modi, A., and Patel, J. (2016). Predicting green product consumption using theory of planned behavior and reasoned action. J. Retail. Consum. Serv. 29, 123-134. doi: 10.1016/j.jretconser.2015.11.006

Sengupta, A. (2015). Competitive investment in clean technology and uninformed green consumers. J. Environ. Econ. Manage. 71, 125-141. doi: 10.1016/j.jeem.2015.03.001

Song, X. N., Lu, Y. J., Shen, L. Y., and Shi, X. P. (2018). Will China's building sector participate in emission trading system? Insights from modelling an owner's optimal carbon reduction strategies. Energy Policy 118, 232-244. doi: 10.1016/j.enpol.2018.03.075

Song, Y. J., Ji, Q., Du, Y. J., and Geng, J. B. (2019). The dynamic dependence of fossil energy, investor sentiment and renewable energy stock markets. Energy Econ. 84:104564. doi: 10.1016/j.eneco.2019.104564

Sulman, B. N., Desai, A. R., Cook, B. D., Saliendra, N. Z., and Mackay, D. S. (2009). Contrasting carbon dioxide fluxes between a drying shrub wetland in Northern Wisconsin, USA, and nearby forests. Biogeosciences 6, 1115-1126. doi: 10.5194/bg-6-1115-2009

Tang, C. S., and Zhou, S. (2012). Research advances in environmentally and socially sustainable operations. Eur. J. Oper. Res. 223, 585-594. doi: 10.1016/j.ejor.2012.07.030
Tao, F., Zuo, Y., and Xu, L. D. (2014). Internet of things and BOM-based life cycle assessment of energy-saving and emission-reduction of products. IEEE Trans. Ind. Inform. 10, 1252-1254. doi: 10.1109/TII.2014.2306771

Xia, Y., Kong, Y. S., Ji, Q., and Zhang, D. Y. (2019). Impacts of ChinaUS trade conflicts on the energy sector. China Econ. Rev. 58:101360. doi: $10.1016 /$ j.chieco.2019.101360

Xu, L., and Wang, C. X. (2018). Sustainable manufacturing in a closed-loop supply chain considering emission reduction and remanufacturing. Resour. Conserv. Recycling 131, 297-304. doi: 10.1016/j.resconrec.2017.10.012

$\mathrm{Xu}$, L., Zhang, Q., and Shi, X. P. (2019). Stakeholders strategies in poverty alleviation and clean energy access: a case study of China's PV poverty alleviation program. Energy Policy 135:111011. doi: 10.1016/j.enpol.2019.111011

Xu, X. F., Wei, Z. F., Ji, Q., Wang, C. L., and Guo, G. W. (2019). Global renewable energy development: influencing factors, trend predictions and countermeasures. Resour. Policy 63. doi: 10.1016/j.resourpol.2019.101470

Xue, J., Gong, R. F., Zhao, L. J., Ji, X., and Xu, Y. (2019). A green supplychain decision model for energy-saving products that accounts for government subsidies. Sustainability 11, 2-17. doi: 10.3390/su11082209

Yalabik, B., and Fairchild, R. J. (2011). Customer, regulatory, and competitive pressure as drivers of environmental innovation. Int. J. Prod. Econ. 131, 519-527. doi: 10.1016/j.ijpe.2011.01.020

Zhang, D. Y., Zhao, R., and Ji, Q. (2019). Green innovation and firm performance: evidence from listed companies in China. Resour. Conserv. Recycling. 144, 48-55. doi: 10.1016/j.resconrec.2019.01.023

Zhang, L. H., Wang, J. G., and You, J. X. (2015). Consumer environmental awareness and channel coordination with two substitutable products. Eur. J. Oper. Res. 241, 63-73. doi: 10.1016/j.ejor.2014.07.043

Zhang, L. H., Xue, B. W., and Liu, X. Y. (2018). Carbon emission reduction with regard to retailer's fairness concern and subsidies. Sustainability 10, 1-28. doi: 10.3390/su10041209

Zhang, Y. X., Xiao, C. C., and Zhou, G. H. (2019). Willingness to pay a price premium for energy-saving appliances: role of perceived value and energy efficiency labeling. J. Clean. Prod. 33, 1-10. doi: 10.1016/j.jclepro.2019.118555

Zhou, W. H., and Huang, W. X. (2016). Contract designs for energy-saving product development in a monopoly. Eur. J. Oper. Res. 250, 902-913. doi: 10.1016/j.ejor.2015.10.024

Zu, Y. F., Chen, L. H., and Fan, Y. (2018). Research on low-carbon strategies in supply chain with environmental regulations based on differential game. J. Clean. Prod. 177, 527-546. doi: 10.1016/j.jclepro.2017.12.220

Conflict of Interest: The authors declare that the research was conducted in the absence of any commercial or financial relationships that could be construed as a potential conflict of interest.

Copyright () 2020 Zhao, Xia, Yu and Liu. This is an open-access article distributed under the terms of the Creative Commons Attribution License (CC BY). The use, distribution or reproduction in other forums is permitted, provided the original author(s) and the copyright owner(s) are credited and that the original publication in this journal is cited, in accordance with accepted academic practice. No use, distribution or reproduction is permitted which does not comply with these terms. 